The problem of nucleation is considered by V. N. Filipovich by discussing a very simple model of a mixture of two particles. As he says, "... success depends on the extent to which the model reflects the real system. The development of a detailed theory of crystallization of complex glasses and melts directly depends on the state of the theory of liquid and glass structure, which is still far from perfection".

The editor of this volume, E. A. Porai-Koshits, has made important contributions to the study of glasses by $\mathrm{X}$-ray diffraction and his laboratory has for some years now concentrated on the use of small-angle $\mathrm{X}$-ray diffraction, light scattering and electron microseopy to study the development of immiscibility in simple glasses and the initiation of crystallization. This experimental work is of a high standard and very useful data on microphase separation in lithium oxide and sodium oxide silica glasses are included.

In the third volume most of the work was concentrated on glasses in the $\mathrm{Li}_{2} \mathrm{O}-\mathrm{Al}_{2} \mathrm{O}_{3}-\mathrm{SiO}_{2}$ system and some papers on erystallization in this system are included in the present volume. In addition glasses containing sodium oxide in place of lithium and/or gallium oxide in place of alumina have been examined. In the alkali aluminosilicate glasses, the devitrification products retain the alumina in the anionic framework, but the gallium glasses give only crystals in which the anionic framework appears entirely of silica.

Work by Toropov and his co-workers on the $\mathrm{MgO}-\mathrm{FeO}-\mathrm{SiO}_{2}$ system shows that thought is still being given to the production of useful ceramic materials from blast furnace slags.

There is a little overlap with the previous volume particularly in the theoretical section and space could have been saved by editorial action; for example, the same argument and the same diagram are repeated on pages 35 and 40. The appearance of this volume so soon after the previous one shows very definitely that these new materials are considered to be of great importance in the U.S.S.R.

R. W. Douglas

\section{UNCERTAIN MATERIAL}

\section{Radiation Damage in Graphite}

By J. H. W. Simmons. (International Series of Monographs in Nuclear Energy, Vol. 102.) Pp. xii $+242+8$ plates. (London and New York: Pergamon Press, 1965.) $80 s$. net.

Radiation Damage in Graphite will be of great value to those who are concerned with the effects of reactor irradiation on the properties of graphite and particularly to those whose interest arises from practical reactor problems. The introductory chapter is followed by a clear account of the physical processes in which the atoms are involved during radiation and a description of the defects which are produced. This is followed by four chapters which describe, in turn, the behaviour of electrical and mechanical properties, thermal and structural properties, the dimensional changes and the mechanical properties. Finally, a full account is given of stored energy effects and the way in which this can be measured and of the phenomena of radiation annealing. Particularly impressive is the series of excellent photographic plates which provide visual evidence of the radiation damage, notably as seen in the electron microscope.

To one who was concerned with the early investigations of this subject it comes as rather a shock to see how illdefined many of the concepts still are. A reader approaching the subject for the first time might well be confused by the mass of data which is available but which, because of the heterogeneity of the radiation and the complications of the damage processes, is very incompletely digested. In assessing this, one is left with much doubt, and certainly no information, about the reliability of some of the experimental results, in a field in which reproducibility is not to be taken for granted. Figs. 45, 56 and 81 provide typical examples of justifiable doubts concerning the data. The theoretical calculations seem to be similarly fraught with difficulties, and it is no surprise to find a note added in proof which, concerning the displacement energy $T_{d}$, says "It now appears that $60 \mathrm{eV}$ is a better value than $25 \mathrm{eV}$, and if this is accepted, the number of displaced atoms given in this book should be reduced by the ratio $25: 60$ ".

The author has achieved a very creditable performance with his cast of eccentrics and has provided a valuable, up-to-date story of his field.

G. E. BACON

\section{EXPERIMENT SIZE IN INDUSTRY}

\section{Sample-Size Determination}

By Arthur E. Mace. Pp. $\mathrm{x}+226$. (New York: Reinhold Publishing Corporation; London: Chapman and Hall, Ltd., 1964.) $96 s$.

THE title of Sample-Size Determination is extremely misleading, suggesting as it does a treatment of an important problem in the design of surveys. The book is, in fact, "ฉ compilation of mathematical procedures for determining the optimum size of a research experiment" and is concerned exclusively with industrial experimentation.

The heart of the book is contained in Chapters 5-7. The first of theso is devoted to the estimation of confidence limits for parameters of normal, binomial, and exponential distributions. Each problem is discussed in a separate section, which begins with an introduction, in which the relevant statistic is described, its distributional properties are stated, and a formula is given for determining the degree of replication required to achieve a confidence interval of specified width; this is followed by an example, and a postscript (a good feature) discussing the robustness of the sampling distributions involved. The examples are presented, in monotonously stereotyped form, as little stories, the hero of which is an engineer ("An engineer wishes to estimate the mean change in resistance of a certain type of $3-\mathrm{Kohm}$ resistor during the first 1,000 hours of a life test"), who usually has to deal with some rather well-informed manufacturers ("The manufacturer ... elaims that knowing the initial resistance value of an individual specimen he would be able to predict the tolerance range for resistance of this specimen after 1,000 hours to within $120 \mathrm{ohms}$ "), and who after a certain amount of arithmetic, laid out in considerable (at times unnecessary) detajl, arrives at a happy ending in the form of a conclusion ("Therefore, the engineer concluded that a sample of 46 specimens of the resistor type should be placed on test").

Chapter 6 is similar in eharacter to Chapter 5, except that it presents its problems in terms of hypothesis testing, with control of errors of the second kind, and Chapter 7 deals with problems of selection.

The examples in these chapters could provide quite a useful 'cook-book' for a reader prepared to tolerate the 'child's guide' flavour of the presentation (though I hope no experimenter would be perverse enough to do an experiment consisting of 160 identical half-replicates of a $2^{3}$ factorial design, as suggested in one example !). The introductions to the examples are unfortunately much less satisfactory. The author's attempt to make each section self-contained has involved him in much unnecessary repetition, while many of these sections are far too condensed to mean much to the sort of reader who needs to have examples spelled out in the detail given here; the writing also is not always as elear as it might be. These criticisms, and especially the last, apply also to the first four (short) chapters, intended to provide a logical founda- 